УДК 378.091.26:796

\author{
Юлія Козерук \\ Національний університет \\ «Чернігівський колегіум імені Т. Г. Шевченка» \\ ORCID ID 0000-0002-8777-1726 \\ Володимир Борисенко \\ Чернігівський національний \\ технологічний університет \\ ORCID ID 0000-0003-0840-6040 \\ Анатолій Денисовець \\ Житомирський національний \\ агроекологічний університет \\ ORCID ID 0000-0002-2440-5630 \\ Кирило Козерук \\ Сумський державний педагогічний \\ університет імені А. С. Макаренка \\ ORCID ID 0000-0002-6918-5627 \\ Наталія Кваша \\ Національний університет \\ «Чернігівський колегіум імені Т. Г. Шевченка» \\ ORCID ID 0000-0002-9406-1917 \\ DOI 10.24139/2312-5993/2019.05/095-104
}

\title{
МЕТОДИ КОНТРОЛЮ В ПРОЦЕСІ ЗАНЯТЬ ФІЗИЧНИМИ ВПРАВАМИ
}

Констатовано, що однією з важливих ланок управління діяльністю в галузі фрізичної культури та спорту є система комплексного контролю, яка дає змогу оцінювати підготовленість організму на всіх етапах процесу фізичного виховання.

Зазначено про важливість упровадження в практику діяльності фрахівців фрізичної культури та спорту комплексного контролю, який передбачає використання як педагогічного, так і медико-біологічного контролю.

Описано низку тестів, що запропоновано використовувати в процесі занять фрізичними вправами зі студентами для оцінки морфо-фрункціональних показників підготовленості організму.

Ключові слова: студенти, методи контролю, фрізичні вправи, рухові якості.

Постановка проблеми. 3 давніх давен у людей виникала потреба у з'ясуванні, хто спритніший, витриваліший, сильніший тощо. Це призводило до утворення видів спорту та організації різноманітних змагань. Для того, щоб успішно займатися будь-яким видом рухової діяльності або обраним видом спорту, необхідно знаті методи контролю за станом організму, як з боку 
педагога, так і в процесі інформальної освіти (Рибалко та ін., 2016). Також це $\epsilon$ важливим завданням у підготовці фахівців галузі фізичної культури та спорту.

Аналіз актуальних досліджень. Діяльність фахівців у сфері фізичної культури та спорту характеризується різноманітним і складним змістом (Чичкан та Кость, 2011). Для досягнення бажаної результативності такий зміст повинен бути певним чином систематизований, підпорядкований чіткій логіці функціонування. У будь-якій цілеспрямованій і раціонально-організованій діяльності можна виокремити такі взаємопов'язані між собою компоненти: планування, реалізація запланованого, контроль і облік результатів (Круцевич та ін., 2012). Наявність, єдність і якість функціонування цих компонентів дозволяє доцільно побудувати заняття фізичними вправами, ефективно керувати педагогічним процесом та його результатами (Печко та ін., 2018).

Контроль $є$ одним із найважливіших елементів управління процесом занять фізичними вправами. Він є основним джерелом отримання інформації про об'єкт, яким управляють після виконаних команд (канал зворотного зв'язку). Основна мета - виявлення адекватності педагогічних впливів та їхніх ефектів запланованим результатам і, за умови виникнення невідповідності, прийняття необхідних рішень щодо корекції дій управління (Костюкевич, 2012). Контролю підлягає й оцінка факторів зовнішнього середовища, метеорологічної інформації, гігієнічних умов занять, обладнання, інвентарю, одягу.

У процесі занять фізичними вправами використовуються два види контролю: педагогічний контроль і самоконтроль. На думку Т. Ю. Круцевич (2011), у віці 13-14 років ці види контролю можна доповнити взаємоконтролем між тими, хто займається. Це твердження стосується й педагога, важливо також здійснювати самоконтроль шляхом самоспостереження та інших методів контролювати власні дії, вчинки, вказівки, повідомлення, звернені на вихованців. Тільки осмислюючи й оцінюючи результати власної діяльності, можна підвищувати якість занять і педагогічну майстерність.

Педагогічний аспект контролю полягає в зіставленні наявних умов і можливостей досягнення передбаченого ефекту. У контролі специфічних чинників чільне місце посідає контроль рухової діяльності як чинника впливу на організм тих, хто займається (Ковальчук та Присакар, 2012). Контроль динаміки функціональних зрушень в організмі $\epsilon$ одним із найбільш розроблених розділів контролю у фізичному вихованні. Зазвичай, цей напрям пов'язаний із медико-біологічним контролем.

Найважливішим у педагогічному контролі за процесом фізичного виховання $€$ контроль за формуванням знань, умінь, навичок, розвитком рухових і вдосконаленням особистих якостей. 
Завдяки контролю та обліку накопичуються дані про фізичний стан, техніко-тактичну підготовленість та кількісні досягнення тих, хто займається (Попичев, 2011). Крім цього, систематично перевіряється ефективність засобів, методів і організаційних форм, які застосовуються, з'ясовується характер ускладнень в освітньому процесі, вольова стійкість і працездатність тих, хто займається. Ці дані дозволяють точніше планувати й коректувати освітній процес, а також використовувати при підведенні підсумків за певний період часу.

Мета дослідження - узагальнити методи контролю за станом організму в процесі занять фізичними вправами зі студентами.

Методи дослідження: аналіз літературних джерел, узагальнення, систематизація, опис.

Виклад основного матеріалу. У сучасній системі фізичної культури та спорту важливе місце належить контролю, на основі якого здійснюється управління процесом рухової та спортивної підготовки різних верств населення (Костюкевич, 2015). Однією з важливих ланок управління діяльністю в процесі занять фізичними вправами є система комплексного контролю, яка дає змогу оцінювати рівень підготовленості на всіх етапах освітнього процесу, а також раціональність обраного напряму підготовки, рівень і динаміку тренованості організму. Комплексний контроль передбачає використання педагогічного та медико-біологічного контролю.

Педагогічний контроль $є$ основним джерелом отримання інформації про стан і ефективність освітньої діяльності. Серед основних завдань зазначено: облік навантажень; оцінка різних сторін підготовленості; визначення можливостей організму для досягнення запланованих результатів.

Основними методами педагогічного контролю $\epsilon$ педагогічні спостереження (Костюкевич, 2105) та контрольні нормативи (тести). Методи медико-біологічного контролю спрямовані на визначення стану здоров'я, рівня фізичного розвитку, біологічного віку та рівня функціональної підготовленості організму.

у процесі занять фізичними вправами зі студентами оцінку морфологічних показників і стану функціональної підготовленості можна здійснювати за допомогою таких тестів:

1. Показник оптимальної маси тіла: Маса тіла, кг Зріст, дм

Критерії оцінки, ум. од.: надмірна - 5,3-4,4; нормальна - 4,3-3,2; недостатня - 3,1-2,8. 
2. Показник пропорційності фізичного розвитку:

$$
\text { Зріст сидячи, см - Зріст стоячи, см } \times 100 \%
$$

\section{Зріст сидячи см}

Цей показник визначає відносну довжину нижніх кінцівок стосовно довжини тулуба. Критерії оцінки: мала довжина - до $87 \%$; пропорційний розвиток - 87-92\%; велика довжина - понад $92 \%$.

3. Показник відношення м'язової сили до маси (\%) визначається за допомогою ручного динамометра. Силу найсильнішої кисті помножити на $100 \%$. Критерії оцінки: середній показник: 65-80\% - для чоловіків, 48$50 \%$ - для жінок.

4. Показник пропорційності окремих частин тіла.

Критерії оцінки:

- співвідношення обхвату грудної клітки до обхвату таза: 10 : 9;

- обхват шиї становить 38 \% обхвату грудей або 2/3 обхвату стегна;

- (обхват правого передпліччя + обхват лівого передпліччя): $2=30 \%$ обхвату грудей;

- (обхват правого + обхват лівого плеча) : 2 = 36 \% обхвату грудей;

- обхват талії = 75 \% обхвату грудей;

- обхват стегна = 60 \% обхвату таза;

- обхват гомілки $=40$ \% обхвату таза.

5. Показники самоконтролю. Якщо запланована робота чи програма занять адаптована до можливостей тих, хто займається, то їхнє самопочуття під час занять має покращуватися й можуть бути такими:

1) самопочуття (три види оцінки - відмінне, добре, задовільне);

2) апетит (три види оцінки - відмінний, добрий, задовільний);

3) маса тіла (реєструється перед заняттями);

4) частота серцевих скорочень (перед заняттями становить у середньому 60-70 уд./хв.). Контролюються частота, ритмічність пульсу, час відновлення після навантаження;

5) артеріальний тиск;

6. Коефіцієнт витривалості. Коефіцієнт витривалості установлюють для аналізу функціонального стану серцево-судинної системи за формулою Кваса: КВ = ЧСС $\times 10:$ Пульсовий тиск.

Пульсовий тиск - це різниця АТ систолічного та АТ диастолічного. Унормі КВ становить 16. Збільшення цього показника свідчить про ослаблення серцево-судинної системи, зменшення - про ії̈ стомлення.

7. Коефіцієнт економічності кровообігу. Коефіцієнт економічності кровообігу (КЕК) установлюють для аналізу функціонального стану 
серцево-судинної системи. Обчислюється за формулою: КЕК = (АТ систолічний - АТ диастолічний) × ЧСС. У нормі КЕК = 2600. Збільшується при перетренуванні.

8. Тест Руф'є. Використовують для аналізу функціонального стану серцево-судинної системи. Усі виміри роблять 3 інтервалом 15 с. У положенні сидячи, після 5-хвилинного відпочинку вимірюють пульс (P1). Потім виконують 20 присідань за 30 с і знов вимірюють пульс у положенні стоячи (Р2). Далі в положенні сидячи, відпочивши 1 хв., знову вимірюють пульс (Р3). Індекс Руф'є обчислюють за формулою: J = 4 (P1 + P2 + P3 ) - 200 : 10. Якщо J менше 0, пристосування до навантажень відмінне; менше 3 високе; 3-5 - добре; 6-10 - задовільне; 11-15 - слабке; більше 15 незадовільне. Зростання індексу J може бути також ознакою перетренованості або перевтоми.

9. Проба Серкіна. Використовують для аналізу системи зовнішнього дихання:

1) перша фаза - встановити час затримки дихання на вдиху в положенні сидячи;

2) друга фаза - виконати 20 присідань за 30 с та знову виміряти час затримки дихання;

3) третя фаза - відпочити 1 хв. стоячи і знову виміряти час затримки дихання в положенні сидячи (табл. 1).

Таблиця 1

\section{Крітерії оцінки}

\begin{tabular}{|l|l|l|l|}
\hline \multicolumn{2}{|c|}{ Категорія випробуваних } & \multicolumn{3}{|c|}{ Фаза } \\
\cline { 2 - 4 } & \multicolumn{1}{|c|}{ Перша } & \multicolumn{1}{|c|}{ Друга } & \multicolumn{1}{|c|}{ Третя } \\
\hline Здорові треновані & 60 і більше & 30 і більше & Більше 60 \\
\hline Здорові нетреновані & $40-55$ & $15-25$ & $35-55$ \\
\hline $\begin{array}{l}\text { Особи з прихованою вадою } \\
\text { кровообігу }\end{array}$ & $20-35$ & 12 і менше & 24 і менше \\
\hline
\end{tabular}

10. Індекс Піньє. Використовують для оцінки фізичного розвитку людини, розраховують за формулою: I = - $(\mathrm{P}+\mathrm{T})$

де: I - довжина тіла (см); Р - маса тіла (кг); Т - обхват грудей (см).

Чим менше цифра, отримана в результаті обчислення, тим кращою $€$ будова тіла (табл. 2).

11. Техніка антропометрії. Скелет разом із м'язами та шкірою дає чітке уявлення про загальні розміри, форму та пропорції тіла. Проводячи вимірювання тіла, використовують так звані антропометричні точки, що мають чітку локалізацію: кісткові виступи, відростки, бугри, краї з'єднання 
кісток, постійні складки шкіри, специфічні шкірні утворення (соски грудних залоз, пупок та ін.), які легко визначаються під шкірою (орієнтири під час огляду, зовнішні орієнтири) і $\epsilon$ антропометричними точками під час вимірювання тіла та його частин.

Табличя 2

Показники фізичного розвитку

\begin{tabular}{|c|c|}
\hline Значення індексу & Оцінка фізичного розвитку \\
\hline Менше 10 & Дуже висока \\
\hline $10-15$ & Висока \\
\hline $16-20$ & Добра \\
\hline $21-25$ & Середня \\
\hline 2530 & Слабка \\
\hline 30 і вище & Дуже слабка \\
\hline
\end{tabular}

Поздовжні розміри тіла в антропометрії встановлюють як відстань між антропометричними точками, орієнтованими у вертикальній площині, поперечні розміри - як відстань між точками, орієнтованими в горизонтальній площині. Вимірювання слід проводити вранці, коли організм ще не зазнав значних фізичних навантажень. Випробуваний перебуває в положенні стоячи, голова - у позиції очноямкововушної горизонталі (верхній край зовнішнього слухового ходу та нижній край лівої очної ямки розташовані в одній горизонтальній площині).

Обчислення поздовжніх розмірів тіла. За допомогою антропометра вимірюється довжина окремих частин тіла:

- довжина тіла (зріст) - висота верхньотім'яної точки над площею опори;

- довжина тулуба - різниця висот між верхньогрудинною та лобковою точками (проекційна відстань між ними);

- довжина верхньої кінцівки - різниця висот між плечовою та пальцевою точками (проекційна відстань між ними);

- довжина плеча - різниця висот між плечовою та променевою точками (проекційна відстань між ними);

- довжина передпліччя - різниця висот між променевою та шилоподібною точками (проекційна відстань між ними);

- довжина нижньої кінцівки - різниця висот між вертлюжною та нижньогомілковою точками (проекційна відстань між ними);

- довжина стегна - довжина нижньої кінцівки з відніманням висоти верхньогомілкової точки;

- довжина гомілки - різниця висот між верхньогомілковою та нижньогомілковою точками (проекційна відстань між ними); 
Обчислення поперечних розмірів тіла. За допомогою товщинного циркуля вимірюються такі поперечні розміри: ширина плечей (між двома плечовими точками); ширина таза (між двома клубковогребеневими точками).

Обчислення обхватних розмірів тіла виконується й за допомогою сантиметрової стрічки в місцях найбільшого розвитку м'яза вимірюють обхватні розміри (або периметри) тіла:

1) обхват грудної клітки (під час вдиху, видиху і в середньому стані), стрічка накладається позаду під нижніми кутами лопаток і попереду над навколососковими кружальцями (у чоловіків) або вище молочних залоз (у жінок);

2) обхват живота (талії), вимірюють під час горизонтального положення в найвужчому місці на талії - приблизно на середині відстані між 10-м ребром і клубковогребеневою точкою;

3) обхват шиї, стрічку накладають горизонтально: попереду вона проходить під щитоподібним хрящем, а позаду розташовується в місці найглибшої увігнутості шиї;

4) обхват плеча вимірюють у ділянці, де найбільш випнутий двоголовий м'яз у напруженому та розслабленому стані;

5) обхват передпліччя, вимірюють на опущеній руці в найтовстішому його відділі;

6) обхват стегна, вимірюють у горизонтальному положенні: безпосередньо під сідничною складкою, а також у середньому відділі стегна;

7) обхват гомілки, вимірюють у найбільш потовщеному відділі м'яза.

12. Каліперометрія. Вимірювання шкірно-жирових складок. Для визначення товщини жирового прошарку за допомогою каліпера вимірюють такі шкіро-жирові складки:

1) на спині - під нижнім кутом правої лопатки (d1);

2) на грудях - на краю правого великого грудного м’яза (d2) (тільки у чоловіків);

3) на животі - праворуч, відступивши 5 см від пупка (d3);

4) на боку - приблизно на середині косого м'яза живота (d4);

5) 10-те ребро (d5);

6) на передній поверхні плеча - приблизно на середині двоголового м'яза (d6);

7) на задній поверхні плеча - приблизно на середині триголового м'яза (d7);

8) у верхній третині латеральної поверхні передпліччя (d8);

9) на передній поверхні правого стегна - над прямим м'язом стегна (d9); 
10) на задній поверхні правої гомілки - на ділянці литкового м'яза (d10).

Отримані морфофункціональні показники обов'язково заносять до карт обстеження для подальшого їх контролю.

Висновки. За результатами наукового пошуку зазначено про важливість контролю в сучасній системі фізичної культури та спорту, на основі якого здійснюється управління процесом рухової та спортивної підготовки різних верств населення, зокрема студентів. Визначено й систематизовано низку тестів для оцінки морфологічних показників і стану функціональної підготовленості, що доречно використовувати в процесі занять фізичними вправами зі студентами.

Перспективи подальших досліджень вбачаємо в застосуванні проаналізованих видів контролю у практичній діяльності.

\section{ЛІТЕРАТУРА}

Козерук, К., Козерук, Ю. та ін. (2018). Методика корекції маси тіла учнів у процесі формального та неформального навчання фізичної культури. Педагогічні науки: теорія, історія, інноваційні технології, 9 (83), 80-91 (Kozeruk, K., Kozeruk, Yu. et al. (2018). Methodology of students' body weight correction in the process of formal and informal learning of the physical culture. Pedagogical sciences: theory, history, innovative technologies, 9 (83), 80-91).

Костюкевич, В. М., Шевчик, Л. М., Сокольвак, О. Г. (2015). Метрологічний контроль у фізичному вихованні та спорті. Вінниця (Kostiukevych, V. M., Shevchyk, L. M., Sokolvak, O. H. (2015). Metrological control in physical education and sports. Vinnytsia).

Круцевич, Т. Ю. (2012). Теорія і методика фізичного виховання. Олімпійська simepamypa, T. 1, 391, T. 2, 366. (Krutsevych, T. Yu. (2012). Theory and Methods of Physical Education. Olympic Literature, Vol. 1, 391, Vol. 2, 366).

Круцевич, Т. Ю., Воробйов, М. І., Безверхня, Г. В. (2011). Контроль у фізичному вихованні dimeŭ, підлітків і молоді (Krutsevych, T. Yu., Vorobiov, M. I., Bezverkhnia, H. V. Control in the physical education of children, adolescents and young people).

Ковальчук, Г. П., Присакар, В. В. (2012). Педагогіка фрізичної культури. Кам'янецьПодільський (Kovalchuk Н. Р., Prysakar, V. V. (2012). Pedagogics of physical culture. Kamianets-Podilskyi).

Печко, О., Горобей, М., Козерук, Ю. та ін. (2018). Формування кінезіологічної компетентності студентів у процесі фізкультурно-спортивної діяльності. Освіта. Інноватика. Практика, 1 (4), 37-43 (Pechko, O., Horobei, M., Kozeruk, Yu. et al. (2018). Formation of the kinesiological competence of students in the process of physical culture and sports activities. Education. Innovation. Practice, 1 (4), 37-43).

Попичев, М. И. (2011). Контрольные тесты по физической подготовке волейболистов. Вісник Чернігівського національного педагогічного університету ім.. Т.Г. Шевченка. Випуск 91. Серія: педагогічні науки. Фізичне виховання та спорт, T. II, 218-223 (Popychev, M. I. (2011). Control tests on physical training of volleyball players. Bulletin of Taras Shevchenko Chernihiv National Pedagogical University. Issue 91. Series: Pedagogical sciences. Physical training and sports, Vol. II, 218-223).

Рибалко, П. Ф., Козерук, Ю. В. та ін. (2016). Теоретико-методичні основи організації самостійних занять фізичними вправами. Вісник Чернігівського начіонального 
педагогічного університету імені Т. Г. Шевченко. Вип. 135. Серія: Педагогічні науки, 213-216. (Rybalko, P. F., Kozeruk, Yu. V. (2016). Theoretical and methodological bases of organization of independent classes of physical exercises. Bulletin of Taras Shevchenko Chernihiv National Pedagogical University. Issue 135. Series: pedagogical sciences, 213-216).

Костюкевич, В. М. (Ред.) (2017). Теоретико-методичні основи контролю у фізичному вихованні ma cпорті (Kostiukevych, V. M. (Ed.) (2017). Theoretical and methodological foundations of control in physical education and sports. Vinnytsia).

чичкан, О. А., Кость, М. М. (2011). Фізичне виховання у схемах. Львів (Chychkan, О. А., Kost, M. M. (2011). Physical education in the schemes. Lviv).

Фурман, Ю. М. (2007). Завдання до лабораторних робіт зі спортивної медицини. Вінниця (Furman, Yu. M. (2007). Tasks for laboratory work on sports medicine. Vinnytsia).

Willmore, J. H., Costill, D. L. (2004). Physiology of sport and execise. Champaign. Illinois: Human Kinetics.

\section{PEЗЮME}

Козерук Юлия, Борисенко Владимир, Денисовец Анатолий, Козерук Кирилл, Кваша Наталия. Методы контроля в процессе занятий физическими упражнениями.

Констатировано, что одним из важных звеньев управления деятельностью в отрасли физической культуры и спорта является система комплексного контроля, которая позволяет оценивать подготовленность организма на всех этапах физического воспитания.

Указано о внедрении в практику деятельности специалистов физической культуры и спорта комплексного контроля, который предусматривает использование как педагогического, так и медико-биологического контроля.

Описан ряд тестов, которые предложено использовать в процессе занятий физическими упражнениями со студентами для оценки морфо-фрункциональных показателей подготовленности организма.

Ключевые слова: студенты, студенты-спортсмены, методы контроля, физические упражнения, двигательные качества.

\section{SUMMARY}

Kozeruk Yuliia, Borysenko Volodymyr, Denysovets Anatoly, Kozeruk Kyrylo, Kvasha Nataliia. Methods of control in the process of doing physical exercises.

Since ancient times people wanted to know who is the most skillful, the most resistant and the strongest. This desire led to the appearance of new kinds of sports and organization of different competitions including power competitions. To go in for any kind of sport one must know methods of control of the condition of the organism both on the part of the teacher and during informal studying. This is an important task for training the experts in physical education and sports.

There are often a lot of arguments about the thought of negative impact of load exercises and real methodologies of using such exercises during general physical training in different kinds of sports, particularly in volleyball for power development. Negative load exercises impact includes: negative influence on the response rate, changing muscles into fat as soon as the person stops training, negative influence on the joints and human height.

One of important branches of operational management in the sphere of physical education and sports is the system of complex control which gives the opportunity to assess 
the readiness of the organism at all stages of educational process, the correctness of the chosen direction of training, the level and the dynamics of the training.

The basic methods of pedagogical control comprise pedagogical observations and control standards (tests). Control checks of the level of motor readiness must be carried twice a year and the results must be recorded in the registry book.

Medical methods of control are directed at defining the health state, level of physical development, physiological age and level of functional readiness of the organism. During training students-sportsmen progress, current or operative kinds of control are used.

Progress control attempts to show the change in the state of training of the studentssportsmen during the long period of training and to compare the initial indices of motor, technical and functional readiness with the same at the end of the year.

Current control characterizes the training effect of separate classes and monitors functional changes of the organism and its response to typical load (heart rate in every 7-10 days).

Operative control shows the effectiveness of one training class by the indices of heart rate, by physical signs (the color of the skin, respiratory rhythm etc.), by subjective feelings (well-being, desire to train, sustain of trainings, activeness at classes, mood).

Key words: students, students-sportsmen, methods of control, physical exercises, motor qualities.

УДК 37.013 .2

Сергій Корольов

Льотна академія Національного авіаційного університету

ORCID ID 0000-0003-0206-6794

DOI 10.24139/2312-5993/2019.05/104-120

\section{ЗАРОДЖЕННЯ ТА ЕВОЛЮЦІЯ ПОНЯТЬ МЕХАНІКИ У СВІТЛІ ПОКРАЩЕННЯ МЕТОДИКИ Ї̈ ВИКЛАДАННЯ}

Пропонується цикл нових комплексних підходів до покращення методики викладання механіки. Раніше запропоновані методи вдосконалення методики ще знаходяться в ужитку, але їх потенціал виявився майже вичерпаним у даний час. Має багатообіцяючі перспективи даний комплексний підхід, який базується на комплексному застосуванні масиву з декількох базових засад, які креативно та нестандартно комбінуються між собою в багатьох варіантах, у залежності від конкретної ситуації. До мінімального масиву засад входять такі, як: використання досвіду з історичної еволюції базових понять механіки; основні поняття з теорії інформації; застосування комп'ютерної техніки та навчальних програмних продуктів; створення великої множини математичних моделей; комбінаторне поєднання базових засад із метою одночасного використання декількох засобів для вирішення конкретної проблеми. Їх комплексне застосування повинне дати мультиплікативний ефект.

Ключові слова: еволюція, механіка, математична модель явища, теорія інформації, діалектична взаємодія, комбінаторне поєднання, мультиплікативний ерект. 